\title{
SIMULATION OF THERMAL PROCESSES IN GREENHOUSE
}

\author{
Sergei Oskin, Dmitry Tsokur, Alexander Voloshin, Konstantin Grigoryev, Ekaterina Tsokur \\ Kuban State Agrarian University named after I.T. Trubilin, Russia \\ kgauem@yandex.ru,dmitry_tsokur@mail.ru, luntik-s@mail.ru, rollip@yandex.ru , \\ sun_kate03@mail.ru
}

\begin{abstract}
Maintaining a greenhouse efficiency throughout the year is an important task for greenhouse economy. One of the main problems in this area is the maintenance of optimal growing and fruiting conditions of crops, in particular, the maintenance of optimal temperatures, regardless of external conditions. The distribution of temperatures inside a greenhouse depends on many factors, including: a design of a greenhouse, its geographical location, a type and capacity of equipment used for heating, its placement inside greenhouses. The presence of a wide range of factors complicates the accurate thermal calculation of a greenhouse and opens up opportunities for computer modelling of thermal processes using modern physical modelling devices. The purpose of modelling thermal processes occurring in a greenhouse is to identify advantages and disadvantages of selected methods of heating a greenhouse in winter, as well as to obtain a model, changing input parameters of which will show the distribution of temperature fields inside a greenhouse. To maintain the temperature in the greenhouse in winter, cable heating systems, air heaters, heat generators, and infrared panels are used. The cable heating system and air heaters were selected for comparative analysis in the framework of this study. The design of the greenhouse and its shape were chosen in accordance with the models of greenhouses used today. Using the Comsol package blocks "Heat Transfer", "Laminar Flow", "Surface-to-Surface Radiation", a wide set of thermal processes was described, the necessary parameters of which were interconnected using "Multiphysics" interface. With the help of "Events" block, a mechanism of maintaining the set temperature was implemented. The main physical and geometric parameters of the objects under study were also introduced. The analysis was carried out for a dynamic mode of the system. As a result of the simulation, thermal fields and air flow directions were obtained for each time interval of the model under study. Based on the data obtained, the analysis was carried out, and graphs of temperature changes for selected objects were constructed. Conclusions are drawn about the influence of a number of factors on energy efficiency of a greenhouse and considered methods of heating. Ways to optimize the operation of greenhouse heating are proposed. The resulting model can be used for further research of unaffected methods of heating and increasing energy efficiency of a greenhouse.
\end{abstract}

Keywords: greenhouses, heating, modelling, thermal processes, Comsol Multiphysics

\section{Introduction}

Temperature, along with humidity, light and the amount of minerals in the soil, is an important factor at all stages of plant development. Together, these factors determine all the processes of vital activity that occur in a plant.

There are some critical temperatures, when approaching which are violations in vital activity of a plant, and when they are reached, the plant dies. For example, for tomato, the temperature below $15^{\circ} \mathrm{C}$ suspends flowering, it slows down at $10{ }^{\circ} \mathrm{C}$ and after a while stops growing, and the temperature of $0.5^{\circ} \mathrm{C}$ leads to death of flowers, and the temperature below - to death of leaves and stem. Not only low temperatures are dangerous: at temperatures above $35^{\circ} \mathrm{C}$, pollen grains stop germinating with prolonged exposure, the leaves die off, and the flowers fall off. When the temperature rises, fruits and leaves get burned which leads to wilting of plants. These values vary depending on a crop, the stage of plant development, and the duration of heat exposure.

There are also optimal temperatures at which the most intensive growth and accumulation of useful substances in the plant is observed. This temperature depends on a cultivated crop, or rather on conditions of its natural growth, as well as, most importantly, on the phase of plant growth (germination, seedlings, flowering, fruiting). Ensuring the optimal temperature in order to increase productivity is one of the most important aspects of greenhouse vegetable growing. It is worth noting that optimal temperatures for soil and air are different. Maintaining this temperature in winter-spring period is possible only with the help of a greenhouse and its heat supply systems.

Currently, there are various ways to heat greenhouses using:

1. systems of cable heating of ground;

2. air heaters;

3. thermal generators;

4. infrared (IR) panels. 
They have different efficiency, design and operational features that determine the feasibility of their use in greenhouses for various purposes. The variety of heating methods and incompleteness of recommendations for their selection and organization for each specific case increase the interest in studying physical processes that occur in the process of heating a greenhouse. Adding knowledge in this area is important for improving the efficiency of greenhouse production.

\section{Materials and methods}

Currently, there are many designs of greenhouses [3]. An arched greenhouse is selected, the side view of which is shown in Fig. 1, for the analysis of processes. The dimensions of the greenhouse are $24.3 \times 7$ and $2 \times 3.8$. The coating of the greenhouse is made of cellular polycarbonate with a thickness of $10 \mathrm{~mm}$. The studies are carried out for meteorological conditions corresponding to the weather conditions of Krasnodar at the beginning of the year. There is a fertile layer of soil, layers of moistened sand for better thermal conductivity and a layer of insulation material to prevent heat leakage into ground in the base of a greenhouse.

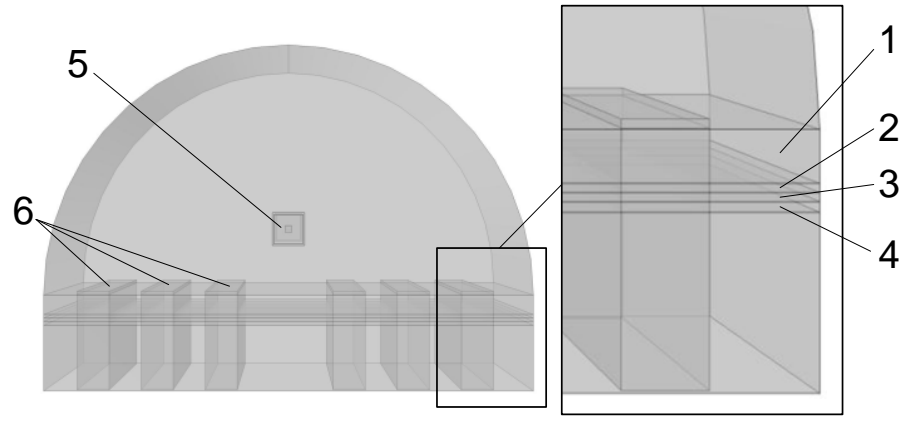

Fig. 1. Greenhouse: 1 - layer of fertile soil; 2 - top layer of sand; 3 - bottom layer of sand; 4 - layer of thermal insulation; 5 - heat gun; 6 - beds

In the first study, the greenhouse was heated resistively using a heating cable located under the beds at a depth of $0.35 \mathrm{~m}$ between layers of sand. Since the cable is laid quite tightly (step $0.15 \mathrm{~m}$ ), it was presented in the form of a solid thin surface in the framework of this model. The heat generated in this way slowly heats the nearest soil layers and, in part, the surrounding air.

The second study is conducted for air heating, which is implemented using heat guns located in vertical walls of the greenhouse. The heat gun shown in Fig. 2 consists of a heating element, a frame and a fan. In this case, the heat energy due to forced circulation is quickly transferred to the air inside the greenhouse. Then, due to small heat capacity of air, the heat is quickly spent on convection losses through the walls of the greenhouse and heating the soil.

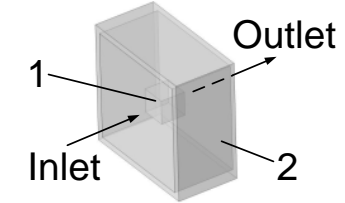

Fig. 2. Air gun: 1 - heating element; 2 - frame

The third study aims to explore the joint use of both methods. From the combination of these methods the best result is expected for heat supply of the greenhouse.

In all studies, the events block implements a mechanism for automatically maintaining the air temperature and the soil layer in a given range. Also, all studies take into account the influence of solar radiation, which is an important source of heat in the system [1].

Thermal conductivity inside the greenhouse is described by the equation:

$$
\rho C_{p} \frac{d T}{d t}+\rho C_{p} u \cdot \nabla T+\nabla \cdot q=Q,
$$

where $\rho$-fluid density, $\mathrm{kg} \cdot \mathrm{m}^{-3}$;

$C_{p^{-}}$heat capacity of the medium, $\mathrm{J} \cdot \mathrm{kg}^{-1} \cdot \mathrm{K}^{-1}$;

$u$ - air velocity, $\mathrm{m} \cdot \mathrm{s}^{-1}$; 
$Q$ - heat rate of thermal source, $\mathrm{W} \cdot \mathrm{m}^{-3}$;

$q$ - thermal flow density, $q=-k \nabla T, \mathrm{~W} \cdot \mathrm{m}^{-2}$;

$k$ - thermal conductivity of air, $\mathrm{W} \cdot \mathrm{m}^{-1} \cdot \mathrm{K}^{-1}$;

$T$ - temperature, $\mathrm{K}$.

The heat flow through walls is described by:

$$
q_{0}=h\left(T_{\text {ext }}-T\right),
$$

where $\quad T_{\text {ext }}$ - external temperature, $\mathrm{K}$;

$h$ - heat transfer coefficient, $\mathrm{W} \cdot \mathrm{m}^{-2} \cdot \mathrm{K}^{-1}$.

Since the walls of the greenhouse are a semi-cylinder, the heat transfer coefficient is calculated by the formula [7]:

$$
h=\frac{k}{D}\left(0.6+\frac{0.387 R a^{1 / 6}}{\left(1+\left(\frac{0,559}{P r}\right)^{9 / 16}\right)^{8 / 27}}\right)^{2},
$$

where $\quad D$-cylinder diameter, $\mathrm{m}$;

$R a$ - Rayleigh number associated with the cylinder diameter $D$

$\operatorname{Pr}-$ Prandtl number.

The coefficient of thermal conductivity for vertical walls [7]:

$$
h=\left\{\begin{array}{l}
\frac{k}{L}\left(0.68+\frac{0.67 R a_{L}^{1 / 4}}{\left(1+\left(\frac{0.492 k}{\mu C_{p}}\right)^{9 / 16}\right)^{4 / 9}}\right) \text { if } R a_{L} \leq 10^{9} \\
\frac{k}{L}\left(0.825+\frac{0.387 R a_{L}^{1 / 6}}{\left(1+\left(\frac{0.492 k}{\mu C_{p}}\right)^{9 / 16}\right)^{8 / 27}}\right)^{2} \text { if } R a_{L}>10^{9}
\end{array}\right.
$$

where $L$ - height of the plate, $\mathrm{m}$;

$\mu$ - fluid viscosity, $\mathrm{mPa} \cdot \mathrm{s}$;

$C_{p}$ - isobaric heat capacity of fluid, $\mathrm{J} \cdot \mathrm{K}^{-1} \cdot \mathrm{mol}^{-1}$.

The total outgoing radiative flux (radiation) is the sum of diffusively reflected and emitted radiation:

$$
J=\rho_{d} G+\varepsilon e_{b}(T),
$$

where $G$-incoming radiative heat flux, or irradiation, $\mathrm{W} \cdot \mathrm{m}^{-2}$,

$\varepsilon$ - surface emissivity, 1 ;

$e_{b}(T)$ - blackbody hemispherical total emissive power, $\mathrm{W} \cdot \mathrm{m}^{-2}$;

$\rho_{d}$ - diffuse reflectivity.

The total incoming radiative flux (irradiation) is split into three contributions according to [7]:

$$
G=G_{m}(J)+G_{a m b}+G_{\text {ext }},
$$

where $G_{m}(J)$ - mutual irradiation coming from other boundaries in the model, $\mathrm{W} \cdot \mathrm{m}^{-2}$;

$G_{\text {ext }}$ - irradiation from external radiation sources, $\mathrm{W} \cdot \mathrm{m}^{-2}$;

$G_{a m b}-$ ambient irradiation, $\mathrm{W} \cdot \mathrm{m}^{-2}$, defined as [7]:

$$
G_{a m b}=F_{a m b} e_{b}\left(T_{a m b}\right),
$$

where $F_{a m b}-$ ambient view factor, 1 ;

$T_{a m b}$-assumed far-away temperature, $\mathrm{K}$.

According to the Stefan-Boltzmann law, the power radiated across all wavelengths depends on the fourth power of temperature:

$$
e_{b}(T)=n^{2} \sigma T^{4},
$$


where $n$-refractive index of the media, 1 ;

$\sigma$-Stefan-Boltzmann constant, $\mathrm{W} \cdot \mathrm{m}^{-2} \cdot \mathrm{K}^{-1}$.

Heat flows in the greenhouse are described by a system of equations:

$$
\left\{\begin{array}{c}
\rho(u \cdot \nabla) u=\nabla \cdot\left[-p I+\mu\left(\nabla u+(\nabla u)^{T}-\frac{2}{3} \mu(\nabla \cdot u) I\right]+F\right. \\
\nabla \cdot(\rho u)=0
\end{array},\right.
$$

where $p$-pressure, $\mathrm{Pa}$;

$I$ - unit matrix;

$F$ - volume force vector, $\mathrm{N} \cdot \mathrm{m}^{-3}$.

\section{Results and discussion}

As a result of calculating the models developed in Comsol Multiphysics, the temperature distributions in the greenhouse for three studies were obtained. The temperature distribution is obtained for specified time intervals with an interval of one hour. Also, graphs of changes in temperature sensors of air and soil are obtained. The total power of both air heaters is $10000 \mathrm{~W}$, the ground heating power is $120 \mathrm{~W} \cdot \mathrm{m}^{-2}$.

The temperature fields obtained in the first study show the temperature distribution presented in Fig. 3. The air temperature in this case does not rise above $12{ }^{\circ} \mathrm{C}$ at noon and $5{ }^{\circ} \mathrm{C}$ at the rest of the time (optimal temperature is $22^{\circ} \mathrm{C}-26^{\circ} \mathrm{C}$ ), with the ground temperature in the range of $18{ }^{\circ} \mathrm{C}-20^{\circ} \mathrm{C}$ ). This temperature distribution gives reason to believe that the use of ground heating in these conditions cannot ensure the maintenance of optimal air temperatures. In addition, it is worth noting that due to inertia of thermal heating and account of solar radiation, the temperature at some points of time rises to the level of $22{ }^{\circ} \mathrm{C}$, which leads to the need for further regulation of ground heating.

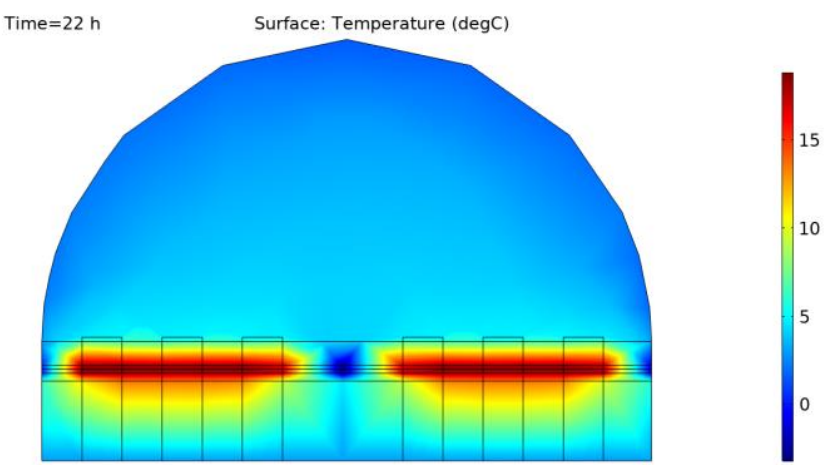

Fig. 3. Temperature fields in the greenhouse when the ground is heated

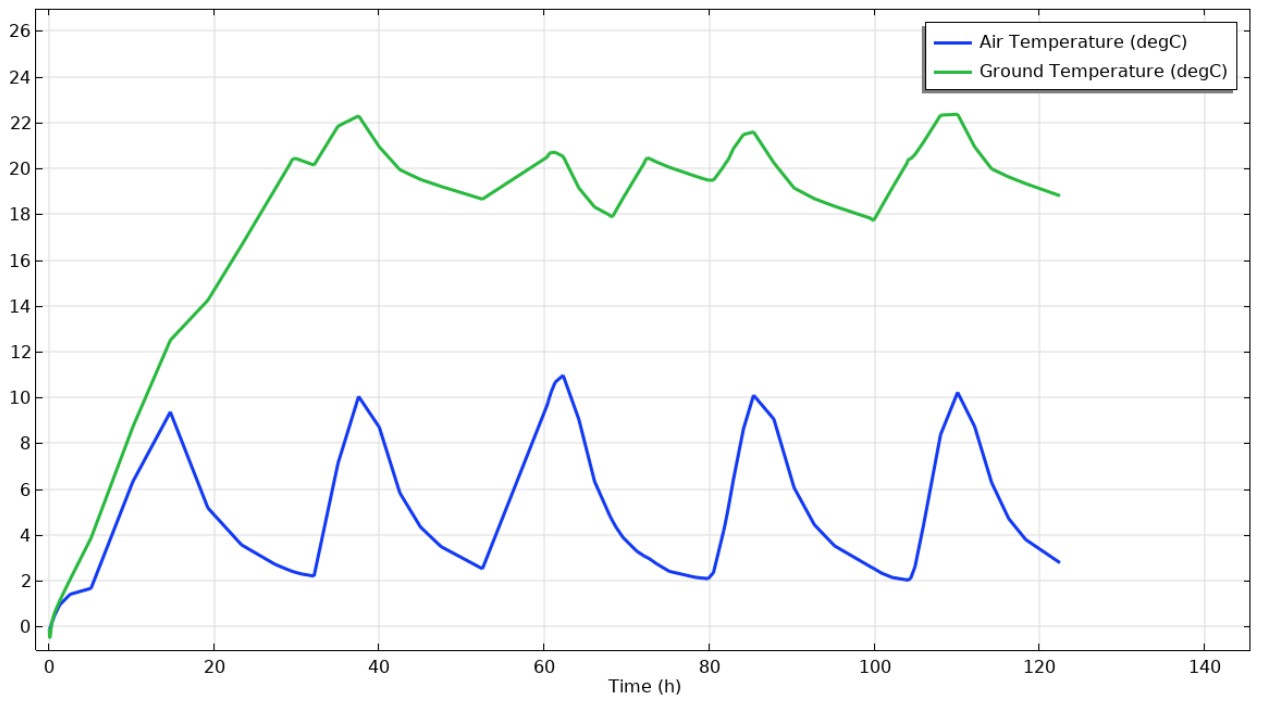

Fig. 4. Chart of changes in the temperature of soil and air in the greenhouse in the first study 
It is also worth noting that when heating the ground with uniform distribution of the heating cable over the area, there is uneven heating, shown in Fig. 5. In order to minimize this unevenness, it is necessary to lay the heating cable in extreme rows of plantings more tightly.

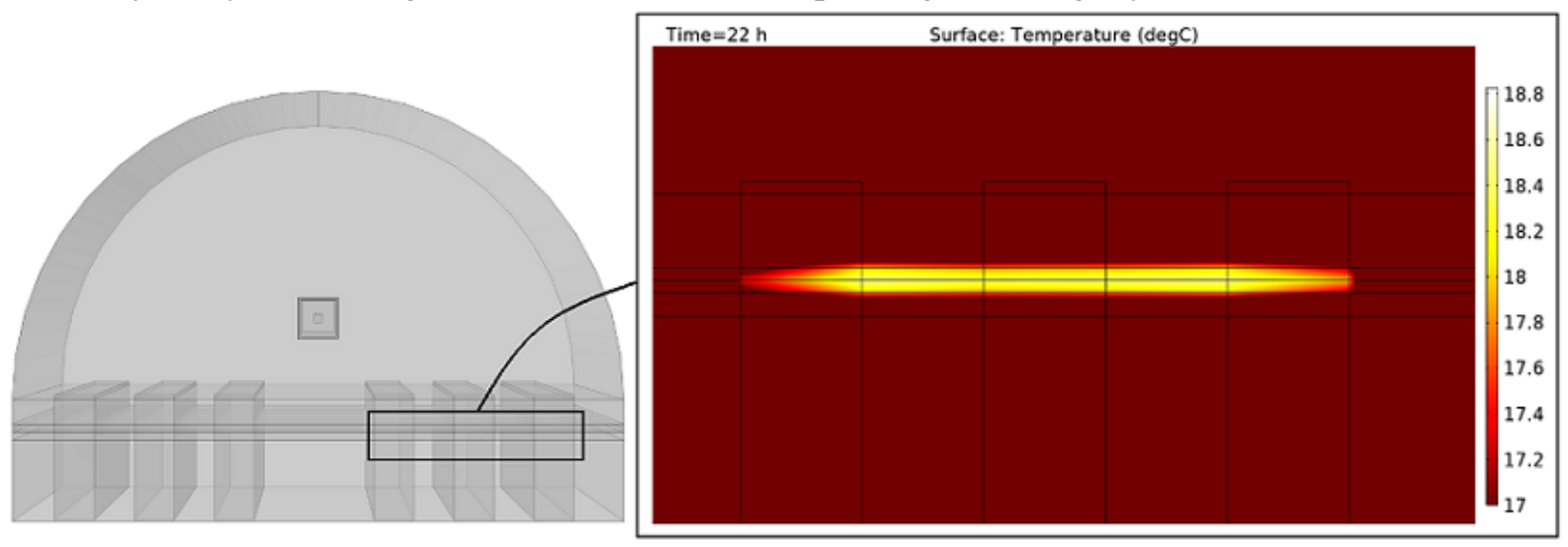

Fig. 5. Uneven warming up during ground heating

The temperature distributions obtained in the second study are shown in Fig. 6. The air temperature is maintained in the range of $22-26^{\circ} \mathrm{C}$, while the soil temperature changes slightly throughout the experiment, excluding the influence of solar radiation. The air temperature in this case is maintained within specified limits due to frequent switching of the air temperature controller.

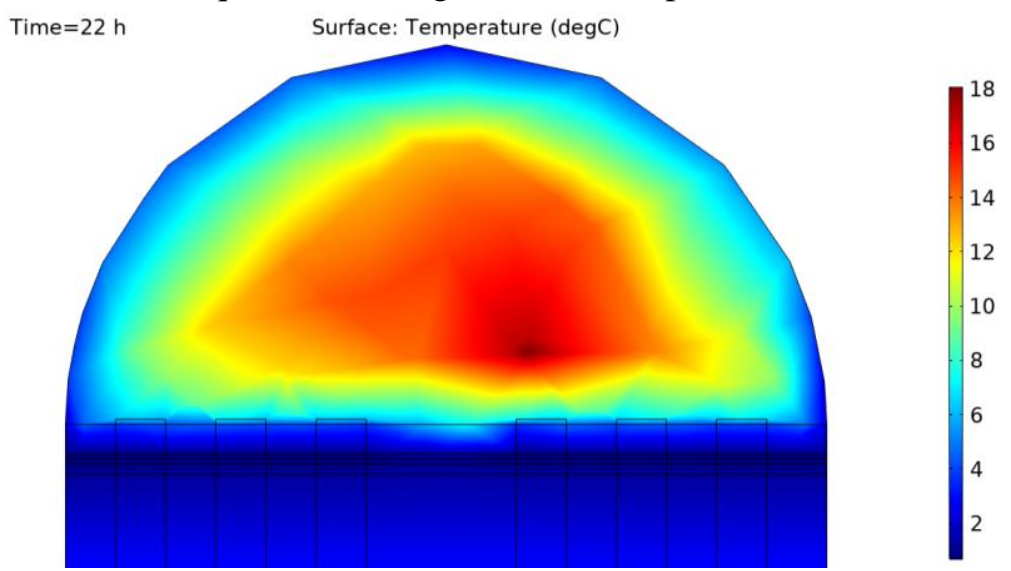

Fig. 6. Temperature fields in the greenhouse when the air is heated

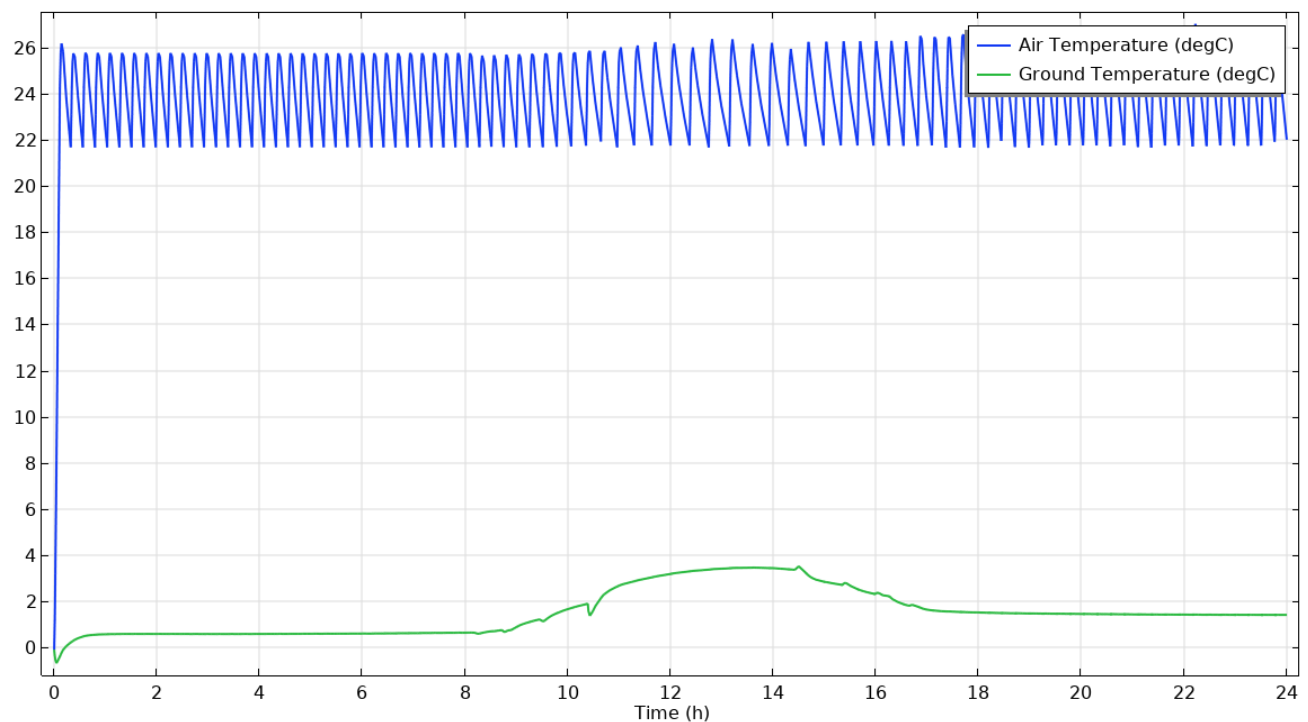

Fig. 7. Chart of changes in the temperature of soil and air in the greenhouse in the second study 
Also, in the course of this study, there was obtained the zone that was undesirable for the growth of plants due to increased temperature during the process of air heating with a heat gun. This area is shown in Fig. 8, its dimensions are $2 \times 1 \mathrm{~m}$. It is necessary to place the heat gun so that the cultivated plants do not appear in this specified area.

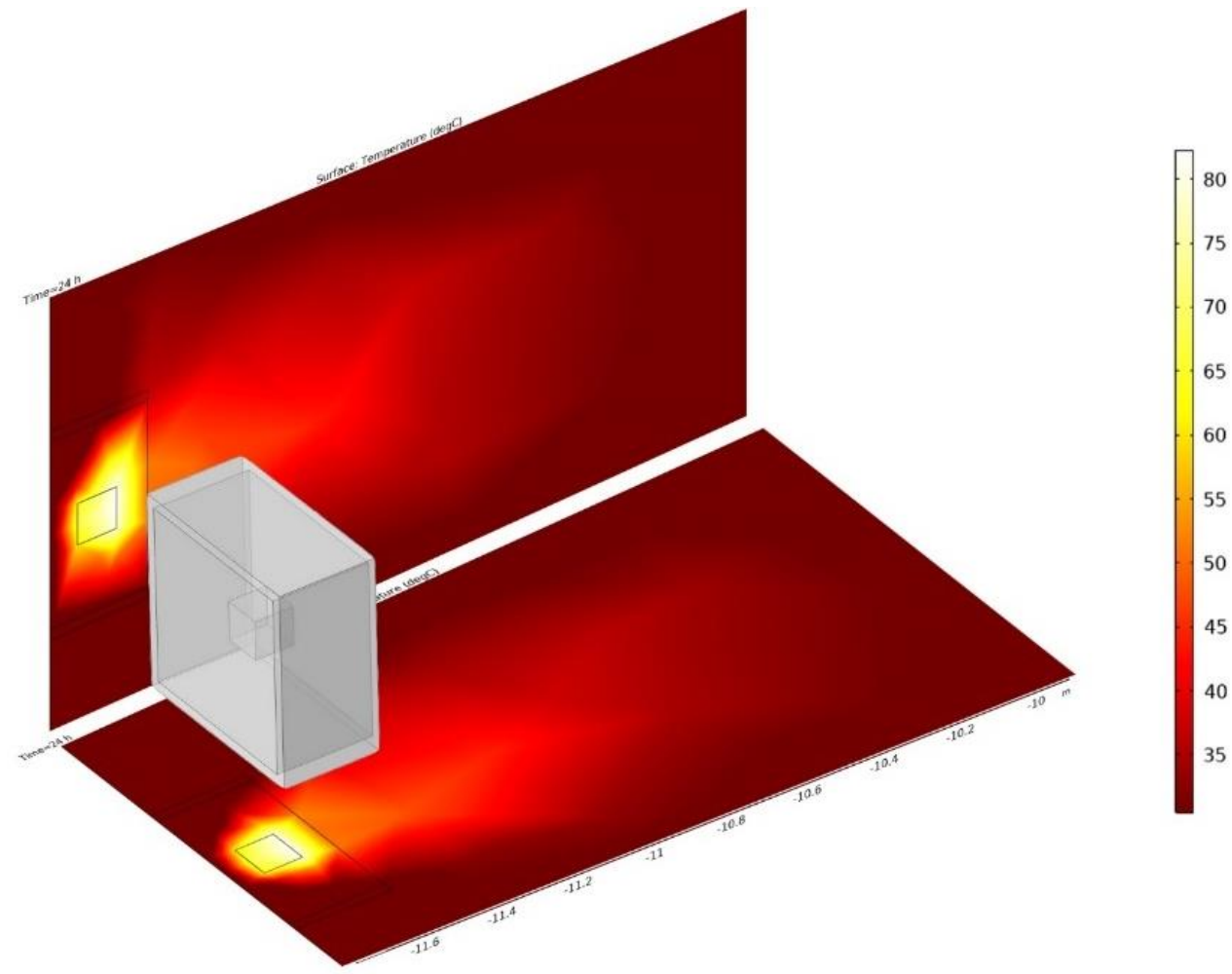

Fig. 8. Area of increased temperature

In the third study, the temperature fields shown in Fig. 9 were obtained. In this case, the temperature of both the air and the ground is maintained at optimal levels. In these weather conditions only this method allowed us to achieve the optimal result. The air temperature ranges from $22{ }^{\circ} \mathrm{C}$ to $26^{\circ} \mathrm{C}$, while the ground temperature ranges from $18{ }^{\circ} \mathrm{C}$ to $20^{\circ} \mathrm{C}$, reaching $22^{\circ} \mathrm{C}$, due to the influence of solar radiation. Since this type of heating was optimal for these conditions, it was decided to calculate the power consumed by the greenhouse. Fixed capacity of air heating is $10000 \mathrm{~W}$, ground heating is $8000 \mathrm{~W}$. The power consumed by air heating was $35 \mathrm{kWh}$, by ground heating is $226 \mathrm{kWh}$ for a period of 46 hours. Accordingly, in this case the power consumption of the greenhouse is $5.67 \mathrm{kWh}$ (137 kW daily).

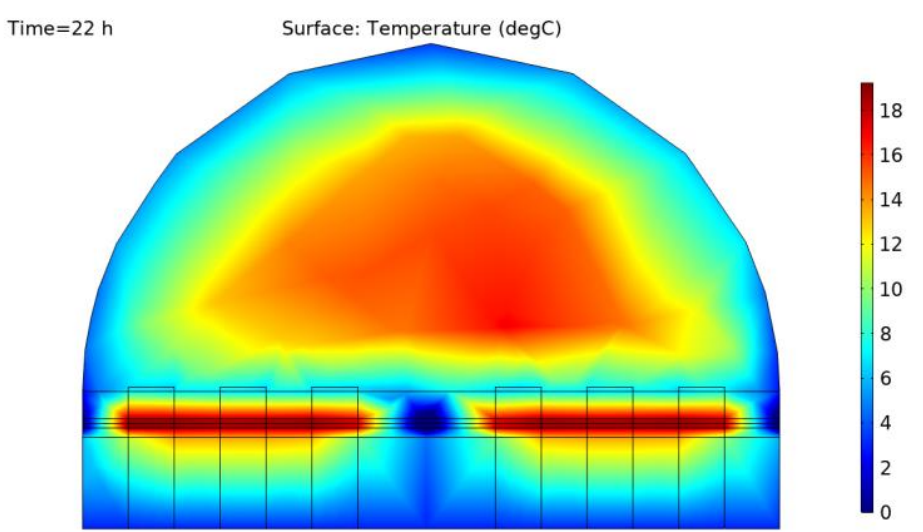

Fig. 9. Temperature fields in the greenhouse under combined heating

The chart of changes in temperatures of soil and air in the greenhouse in the third study is shown on Fig. 10. 


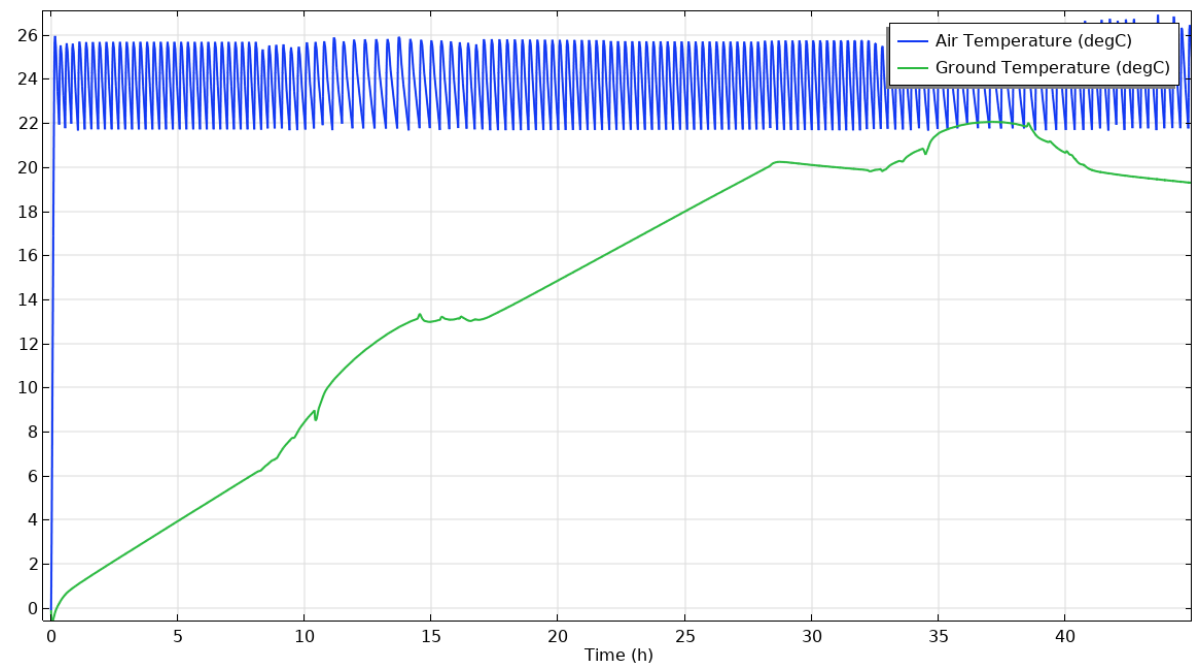

Fig. 10. Chart of changes in temperatures of soil and air in the greenhouse in the third study

\section{Conclusions}

The resulting model of the greenhouse allows us to visualize the changes in thermal fields during the entire heating process. The methods of greenhouse heating are analysed. In this study, in present climatic conditions, the effective heat supply of the greenhouse can only be achieved by the combined heating method. The selected capacities correspond to those necessary to maintain optimal greenhouse temperatures. The power consumed by air heating was $35 \mathrm{kWh}$, by ground heating was $226 \mathrm{kWh}$ for a period of 46 hours. Accordingly, in this case the power of the greenhouse is $5.67 \mathrm{~kW}$ (137 kWh power consumption daily). In order to minimize this unevenness in heat distribution of the heating cable, it is necessary to lay it in extreme rows of plants more tightly.

Also, in the course of this study, the zone was obtained that was undesirable for the growth of plants due to increased temperature during the process of air heating. Its dimensions are $2 \times 1 \mathrm{~m}$. To increase the service life of switching devices of the regulator, the dead zone for this variety of plants should be taken in maximum.

\section{References}

[1] Pavlov M., Lukin S., Derevianko O. Modeling of greenhouse radiant heating. MATEC Web of Conferences, 2018.

[2] Zhang Y., Wang X., Ma Y. etc. Simulation and Experiments of Active Greenhouse Heating System. Elektronika i Elektrotechnika, 2019.

[3] Dalai S., Tripathy B., Mohanta S. etc. Greenhouses: Types and Structural Components, 2020.

[4] Sethi V.P. On the selection of shape and orientation of a greenhouse: Thermal modeling and experimental validation. Solar Energy, 2009. pp. 21-38.

[5] Sethi V.P., Sumathy K., Lee Chiwon. etc. Thermal modeling aspects of solar greenhouse microclimate control: A review on heating technologies. Solar Energy, 2013. pp. 56-82.

[6] Gupta D., Tiwari K., Santosh D.T. Thermal Modeling of an Empty Greenhouse for Subtropics. International Journal of Current Microbiology and Applied Sciences, 2019. pp. 753-763.

[7] Heat Transfer Module User's Guide. COMSOL. 